\title{
Gallbladder Infection
}

National Cancer Institute

\section{Source}

National Cancer Institute. Gallbladder Infection. NCI Thesaurus. Code C78306.

An acute or chronic infectious process affecting the gallbladder. 